\title{
Histopathological Alteration in STZ-Nicotinamide Diabetic Rats, a Complication of Diabetes or a Toxicity of STZ? \\ Nahid MH Elamin ${ }^{1 *}$, IMT Fadlalla ${ }^{2,3}$, Shadia A Omer ${ }^{3}$ and Hala AM Ibrahim ${ }^{4}$
}

\author{
${ }^{1}$ Department of Maxillofacial Surgery and Diagnostic Science, College of Dentistry, Jazan University, Saudi Arabia \\ ${ }^{2}$ Department of Biochemistry, College of Medicine, Imam Abdulrahman Bin Faisal University, Saudi Arabia \\ ${ }^{3}$ Department of Biomedical Science, College of Veterinary Medicine, Sudan University of Science and Technology, Sudan \\ ${ }^{4}$ Department of Microbiology Pathology and Parasitology, College of Veterinary Medicine, Sudan University of Science \\ and Technology, Sudan
}

*Corresponding author: Nahid MH Elamin, Department of Maxillofacial Surgery and Diagnostic Science, College of Dentistry, Jazan University, Saudi Arabia, Tel: 00-96-653-723-9570

\begin{abstract}
Background: Type 2 diabetes mellitus (T2DM) previously known as non-insulin dependent diabetes mellitus is the most common type of diabetes mellitus. The rapid increasing prevalence, high morbidity and mortality of the disease must be encountered by an increase in scientific research. Animal models are very important in the preclinical studies to validate the use of new drugs. Streptozotocin - nicotinamide (STZ-NA) is used to induce T2DM in animals.
\end{abstract}

Aim: The aim of this study was to assess STZ-NA as a model of T2DM and to investigate the causative factors that lead to hepatic histopathological changes.

Methodology: Twenty-five male Wistar rats were divided into four groups. One normal non-diabetic control group (NNC) ( $n=6)$, two diabetic groups subdivided into non-treated diabetic group (NTD) $(n=6)$ and metformin treated diabetic group (MTD) $(n=7)$ and the fourth group was composed of rats failed to develop diabetes [failed induction group $(F I G)](n=6)$. Diabetes was induced by a single intraperitoneal injection of STZ (65 mg/kg-bw) $15 \mathrm{~min}$ after intraperitoneal administration of nicotinamide $(120 \mathrm{mg} / \mathrm{kg}$ bw). Induction of diabetes was confirmed after 72 hours by fasting blood glucose $(F B G) \geq 250 \mathrm{mg} / \mathrm{dl}$. 8 weeks after induction, oral glucose tolerance test was performed; blood samples were taken for analysis of lipid profile, urea, creatinine and hepatic enzymes; samples from the liver were prepared for histopathological study and samples from the skeletal muscles were taken for determination of insulin receptor content by Elisa.

Results: Metformin improved glucose intolerance. Serum high density lipoprotein cholesterol (HDL-C) was significantly reduced in the NTD group compared with the NNC group
( $P$ value 0.006 ) whereas no significant difference in low density lipoprotein cholesterol and triglycerides detected. Skeletal muscle insulin receptor was reduced in both diabetic groups yet, reduction was significant in MTD group compared with NTD group [P values were (0.01) and (0.06) in the MTD and NTD respectively]. Hepatic enzymes, urea and creatinine were within normal range. Histopathological study revealed hepatic histopathological alterations which were more obvious in NTD compared with MTD and FIG.

Conclusion: Our study showed that STZ-NA is a good model for T2DM regarding hyperglycemia, response to metformin, dyslipidemia and the histopathological changes. In addition, it emphasized that hepatic hydropic degeneration of the hepatocytes was a consequence of diabetes rather than STZ.

\section{Keywords}

Type 2 diabetes mellitus, STZ-nicotinamide, Diabetic model, Insulin receptor, Hydropic degeneration, HDL-C, Insulin receptor
Abbreviations
DM: Diabetes Mellitus; T2DM: Type2 Diabetes Mellitus; STZ: Streptozotocin; NA: Nicotinamide; STZ-NA: Strep- tozotocin-Nicotinamide; PARP-1: Poly (ADP-ribose) Poly- merase-1; FI: Failed Induction Group; NTD: Non-Treated Diabetic Group; MTD: Metformin Treated Diabetic Group; NNC: Normal Non-Diabetic Control Group; FBG: Fasting Blood Glucose; i.p: Intraperitoneal; IR: Insulin Receptor; ROS: Reactive Oxygen Species; $1 \mathrm{hr}$ PP: $1 \mathrm{hr}$ Post Prandial; 2hr PP: 2hr Post Prandial

Citation: Elamin NMH, Fadlalla IMT, Omer SA, Ibrahim HAM (2018) Histopathological Alteration in STZ-Nicotinamide Diabetic Rats, a Complication of Diabetes or a Toxicity of STZ?. Int J Diabetes Clin Res 5:091. doi.org/10.23937/2377-3634/1410091

Accepted: September 04, 2018: Published: September 06, 2018

Copyright: (C) 2018 Elamin NMH, et al. This is an open-access article distributed under the terms of the Creative Commons Attribution License, which permits unrestricted use, distribution, and reproduction in any medium, provided the original author and source are credited. 


\section{Introduction}

Diabetes mellitus (DM) is a metabolic heterogeneous syndrome [1] characterized by hyperglycemia, which results from defective insulin secretion or function [2]. The prevalence of DM is increasing worldwide. It is estimated that by year 2030 more than 360 million individuals will suffer from diabetes [3]. T2DM accounts for $90-95 \%$ diabetic cases. Increasing morbidity and mortality necessitates more research in pathogenesis of complications, as well as efficacy of therapeutic agents [4]. T2DM is a complex disorder in which genetic and environmental factors interact and contribute to establishment of the disease. It is strongly related to obesity and characterized by insulin resistance and hyperinsulinemia [5]. Animal models represent an essential step in the preclinical studies of new drugs. The efficacy of the use of them is not only due to the notable anatomical and physiological similarities between humans and animals but also to the fact that most human diseases affect animals and veterinary drugs used to treat animals are very similar to those used to treat humans [6]. Animal models of DM can be obtained either spontaneously (genetic) or non-spontaneously (induced). Genetic models of diabetes have characteristic features mimics diabetes in humans nevertheless, they are homogeneous unlike heterogeneous disease seen in humans also they are expensive. These factors diverted researchers to induced models, which can be achieved chemically, surgically, by gene knockout or diet manipulation [1]. STZ (2-deoxy-2-(3-methyl-3-nitrosourea)-1-D-glucopyranose) [7] - an antibiotic synthesized by Streptomycetes achromogenes - is one of the most commonly used diabetogenic agents because of being cheap and having less side effects [8]. It is used to induce type 1 as well as T2DM when combined with nicotinamide (NA) [9]. It is highly selectively toxic to $\beta$ cells of the pancreas. Selectivity is due to the hexose moiety that helps it cross the cell membrane via GLUT2 [7]. Mechanism of toxicity of STZ includes alkylation of DNA by transfer of the methyl group from STZ to the DNA molecule resulting in the fragmentation of the DNA. This overstimulates poly (ADP-ribose) polymerase-1 (PARP1) diminishing cellular NAD+ (substrate of PARP), and subsequently ATP, and finally results in beta cell necrosis. Other mechanisms of toxicity of STZ include generation of reactive oxygen species (ROS), NF-KB, generation of nitric oxide [10], reduction of mitochondrial membrane potential and activation of c-Jun N-terminal kinase. Nicotinamide (pyridine-3-carboxamide) -an active form of vitamin B3 (niacin)- is an antioxidant agent. It is essential to the coenzymes NADH and NADPH and then for numerous enzymatic reactions in the body including formation of ATP. It partially protects pancreatic $\beta$-cells from harmful effects of STZ by inhibition of PARP1, increasing biosynthesis of NAD+ and scavenging free radicals [11] NA when administered prior to STZ leads to loss of early phase of glucose stimulate insulin secretion which is a feature of T2DM [12]. Thus, injection of NA prior to the administration of STZ partially protects beta cells and produces diabetes that resembles T2DM [13].

\section{Effect of Drugs and Diabetes on the Liver}

Abnormal levels of liver enzymes might be found in asymptomatic healthy individuals while patients with liver disease may show normal hepatic enzymes [14]. Liver enzymes reflect hepatocyte integrity or cholestasis, the later increases ALP level [15] whereas ALT is elevated whenever there is hepatocyte injury [16]. Liver disease can be divided into different categories according to ALT and ALP level and the ratio between them [17]. Both STZ and DM can cause hepatic histopathological changes. One of the common histopathological changes seen in STZ induced diabetic rats is hydropic degeneration [18]. Hydropic degeneration - a cytoplasmic injury due to massive influx of water leading to cellular swelling and cytoplasmic vacuolation - may be induced by ROS [19]. There are several factors that lead to hydropic degeneration (vacuolation) including; drugs, viral hepatitis, cholestasis or fatty liver disease [20]. Another histopathological changes could be seen in diabetic rats are dilation and congestion of the central veins which are triggered by ROS [21]. The mechanism of dilation and congestion of the central veins starts with damage of endothelial cells of the sinusoids by ROS that leads to activation of coagulation which in turn causes sinusoidal obstruction and ultimately dilation of central veins [22].

\section{Alteration of Insulin Receptor and/or its Si- gnaling Pathway in Diabetes}

The skeletal muscle accounts for $\sim 75 \%$ of whole-body post prandial glucose uptake [23]. It expresses GLUT4 on its membrane. Unlike other glucose transporters, GLUT4 is kept in vesicles until insulin binds to its receptor causing translocation of GLUT4 to the cell membrane. Insulin receptor is a tyrosine-specific protein kinase that is composed of two extracellular $\alpha$ and two transmembrane $\beta$ subunits [24]. Insulin binding to the $\alpha$-subunit results in receptor dimerization and autophosphorylation of the $\beta$-subunit which in turn increases its reactivity toward tyrosine phosphorylation of other substrates $[25,26]$. Insulin is released from beta cells of the pancreas in response to hyperglycemia then binds to its receptor leading to intracellular signaling cascades that finally result in the translocation of the GLUT4 to the plasma membrane reducing blood glucose. On the other hand, reduction of insulin leads to removal of GLUT4 by endocytosis to be kept in vesicles until insulin level rises again [24]. Insulin resistance is an early defect in T2DM. It results in hyperglycemia that further stimulates insulin secretion leading to hyperinsulinemia which in turn leads to down regulation of insulin receptors reducing sensitivity and exacerbating the condition. At the start, beta cells of the pancreas release more insulin to compensate hyperglycemia but the persistent stimulus may lead to progressive loss of beta function and 
insulinopenia [27]. Recent studies revealed that down regulation of insulin receptor contribute to insulin resistance and predispose to T2DM [28].

\section{Effect of Diabetes on Lipid Profile}

Reduction of high-density lipoprotein cholesterol (HDL-C) is a manifestation of dyslipidemia seen T2DM [29]. HDL-C improves glucose uptake by skeletal muscles and stimulates secretion of insulin from pancreatic beta cells, therefore reduction of HDL-C concentration in T2DM is not only a consequence of diabetes but also may contribute to worsening of diabetes as well as progression of prediabetes to frank DM [30].

\section{Materials and Methods}

Prior to the commencement of the study, ethical clearance was obtained from the ethical committee of Faculty of Veterinary Medicine. Sudan University of Science and Technology.

\section{Chemicals}

Streptozotocin, nicotinamide and glucose were obtained from Sigma Chemical Company. St. Louis. USA, rat insulin receptor Elisa kit was purchased from SinoGeneClon Biotech Co. Ltd. China and Onetouch glucometer was purchased from Al nahdi pharmacy. Saudi Arabia.

\section{Animals}

The study was conducted on 25 adult Wistar rats (average body weight $90-150 \mathrm{~g}$ ) kept in special cages at temperature of $\left(37^{\circ} \mathrm{C}\right)$ with a $12: 12$-h light: dark cycles and had free access to water and food for 2-weeks adaptation period prior to the study. A group of 6 normal non-diabetic rats (NNC) was formed then rats were injected with STZ and NA for induction of diabetes. 6 rats injected with STZ and NA but did not develop diabetes were grouped as failed induction group (FI) $(n=6)$. Then animals developed diabetes, were subdivided into two groups; non-treated diabetic group (NTD) $(n=6)$ and metformin treated diabetic group (MTD) $(n=7)(120 \mathrm{mg} / \mathrm{kg}-\mathrm{bw})$.

\section{Induction of diabetes and experimental procedure}

Animals were fasted for 12 hours to avoid competition of glucose with STZ at GLUT2 transporters and hence failure of induction. Diabetes was induced by a single intraperitoneal (i.p) injection of STZ (65 mg/kg-bw) dissolved in a freshly prepared $0.1 \mathrm{M}$ citrate buffer, $(\mathrm{pH}$ 4.5) 15 minutes after i.p injection of NA $(120 \mathrm{mg} / \mathrm{kg}$ bw) dissolved in normal saline. Then rats were given $5 \%$ glucose solution for overnight to counter drug induced hypoglycemia. 72 hours after induction, blood samples were collected from the tail vein of rats by pricking for the estimation of blood glucose with Onetouch glucometer. Diabetes was confirmed by FBG of $\geq 250 \mathrm{mg} / \mathrm{dl}$.

\section{Investigations}

\section{Biochemistry}

At the end of the $8^{\text {th }}$ week, oral glucose tolerance test
(OGTT) was performed. Glucose tolerance was assessed by giving rats an oral load of glucose $(2 \mathrm{~g} / \mathrm{kg}$. b.w) after 12 hours fasting. Blood samples were collected from the tail tip incision at 0,60 , and 120 minutes after the glucose load. Blood glucose was checked using glucometer and blood glucose concentration was plotted against time. After that, blood was collected then plasma was stored at $4{ }^{\circ} \mathrm{C}$ for measurement of hepatic enzymes, urea, creatinine, triglycerides (TG) low-density lipoprotein cholesterol (LDL-C) and HDL-C.

\section{Histopathological preparation}

Histopathological examination was done according to the methods described by Banchroft, et al. [31]. At the end of the experiment, the tested animals were given ketamine as an aesthetic then sacrificed. Liver specimens were fixed in $10 \%$ formal saline, dehydrated through graded alcohols and cleared using two changes of xylene then embedded in paraffin wax. Serial transverse sections of 4-5 micron thickness were prepared using the microtome then stained by Haematoxylin and eosin (H \& E).

\section{Detection of IR by Elisa}

The skeletal muscle is a critical site in T2DM not only because it expresses GLUT4 which is insulin dependent but also due to the high percentage of glucose uptake ( 75\%). Recently insulin insensitivity is found to be associated with downregulation of insulin receptor gene expression.

Skeletal muscles' samples from gastrocnemius muscles were kept in $-80{ }^{\circ} \mathrm{C}$ prior to preparation for detection of insulin receptor by Elisa. Samples were cut, weighed, PBS was added then samples were rapidly frozen in liquid nitrogen. After melting samples were homogenized, centrifuged for 20 minutes at speed of 3000 then the supernatant was preserved in $-20{ }^{\circ} \mathrm{C}$. Wash buffer was prepared by adding $20 \mathrm{ml}$ of wash buffer concentrate to $580 \mathrm{ml}$ of distilled water and standard sample was prepared by making different concentrations in five tubes. The first tube was left blank representing zero standard whereas the undiluted one (fifth) served as the highest standard.

\section{Assay procedure}

$50 \mu \mathrm{l}$ standard were pipetted to the testing standard wells and $40 \mu \mathrm{l}$ sample dilution to the testing sample wells then $10 \mu \mathrm{l}$ of supernatant were added to testing sample wells and mixed gently. After 30 minutes of incubation at $37{ }^{\circ} \mathrm{C}$, liquid was discarded then wells were washed by washing buffer (five cycles). $50 \mu \mathrm{l}$ HRP-Conjugate reagent were added to each well except the blank well, incubated for 30 minutes at $37{ }^{\circ} \mathrm{C}$ then washed. $50 \mu \mathrm{l}$ Chromogen Solution A and $50 \mu \mathrm{l}$ Chromogen Solution B were added to each well for $15 \mathrm{~min}$ at $37^{\circ} \mathrm{C}$ after that $50 \mu \mathrm{l}$ Stop Solution was added to each well to stop the reaction. For calculation, blank well was considered as zero, absorbance was read at $450 \mathrm{~nm}$. 


\section{Statistical analysis}

Data analysis was performed using SPSS program version 21. ANOVA test was used to compare the means of different groups. A statistical significance level of 0.05 was chosen.

\section{Results}

T2DM rat model was induced using combination of STZ and NA. NA is known to have protective effect yet, STZ is lethal to animals. Therefore, we started with more number of rats per group. Percentage of failure of induction was $\approx 36.5 \%$. During the first $72 \mathrm{hrs}$ animals were observed for their behavioral, neurological and autonomic profiles. Rat did not show any of signs mentioned. After a period of $72 \mathrm{hrs}$, animals were observed for mortality. Mortality observed in diabetic rats was $\approx 29 \%$ towards the end of the experiment.

\section{Biochemistry}

\section{OGTT}

At the end of the eighth week of the study, OGTT was performed. After $12 \mathrm{hrs}$ of fasting, rats were challenged with $2 \mathrm{~g} / \mathrm{kg}$-bw glucose. Blood samples were collected from the tail tip incision at 0,60 , and 120 minutes after the glucose load. Blood glucose was estimated using a glucometer (one touch glucometer). NTD showed significant elevation of fasting blood glucose (FBG) level compared with the NNC (P value 0.005 ) whereas elevation of FBG was insignificant in MTD ( $P$ value = 0.63). Elevation of $1 \mathrm{hr}$ PP was significant in MTD ( $P$ value $=0.003)$ while it was highly significant in NTD (P value $=0.000) 2$ hrs PP glucose was significantly high in both MTD and NTD ( $P$ values were 0.021 and 0.005 respectively). OGGT is illustrated in Figure 1.

\section{Hepatic enzymes and renal function}

Hepatic enzymes; alanine aminotransferase (ALT) and alkaline Phosphatase (ALP) were within normal range with no significant difference between groups.
There was no significant change in serum creatinine in all groups. On the other hand, there was a significant increase in blood urea in diabetic groups nevertheless, readings, were within normal range. Table 1 shows hepatic enzymes, blood urea and serum creatinine.

\section{Lipid profile}

Table 1 showed level of HDL-C, LDL-C and TG in all groups. Lipid profile is an important parameter in T2DM. All groups have normal TG level. In spite of occurrence of difference between readings, it was not significant. LDL-C levels were also normal within all groups with no significant variation. On the other hand, HDL-C was significantly low in NTD ( $P$ value $=0.006)$ when compared with NNC.

\section{Histopathological findings}

The architecture of the liver was disturbed in the diabetic groups and the FI group (rats received STZ with failure of induction), when compared to normal structural features of control. In the normal control group, the histopathological examination of liver tissue showed normal appearance of hepatocytes at the level of their cell membrane, nuclei or even cytoplasm. In addition, no congestion or dilation in portal veins were observed. Hepatic tissue section of NTD group showed significant vacuolation with significant

Table 1: Hepatic enzymes, urea creatinine and lipid profile.

\begin{tabular}{|l|l|l|l|}
\hline Groups & MTD & NTD & NNC \\
\hline Mean of ALT (U/L) & $18.6 \pm 6$ & $36 \pm 11$ & $26 \pm 7$ \\
\hline Mean of ALP (U/L) & $136.3 \pm 16.6$ & $127 \pm 000$ & $127 \pm 000$ \\
\hline $\begin{array}{l}\text { Mean of creatinine } \\
\text { (mg/dl) }\end{array}$ & $0.69 \pm 0.2$ & $0.97 \pm 0.1$ & $0.8 \pm 0.02$ \\
\hline Mean of Urea $(\mathrm{mg} / \mathrm{dl})$ & $43.3 \pm 9$ & $39 \pm 12$ & $26.3 \pm 4$ \\
\hline Mean of LDL $(\mathrm{mg} / \mathrm{dl})$ & $47 \pm 14$ & $38 \pm 4$ & $54 \pm 16$ \\
\hline Mean of TG $(\mathrm{mg} / \mathrm{dl})$ & $87 \pm 34$ & $70 \pm 14$ & $76 \pm 41$ \\
\hline Mean of HDL $(\mathrm{mg} / \mathrm{dl})$ & $97.6 \pm 26$ & $80.8 \pm 4$ & $122 \pm 23$ \\
\hline
\end{tabular}

Reduction of HDL was significant in the NTD ( $P$ value = $0.006)$ whereas it was insignificant in the MTD (P value $=0.6)$. Alterations of other parameters (ALT, ALP, creatinine, urea, LDL and TG) were insignificant ( $P$ value $>0.05)$ in both groups (MTD and NTD).

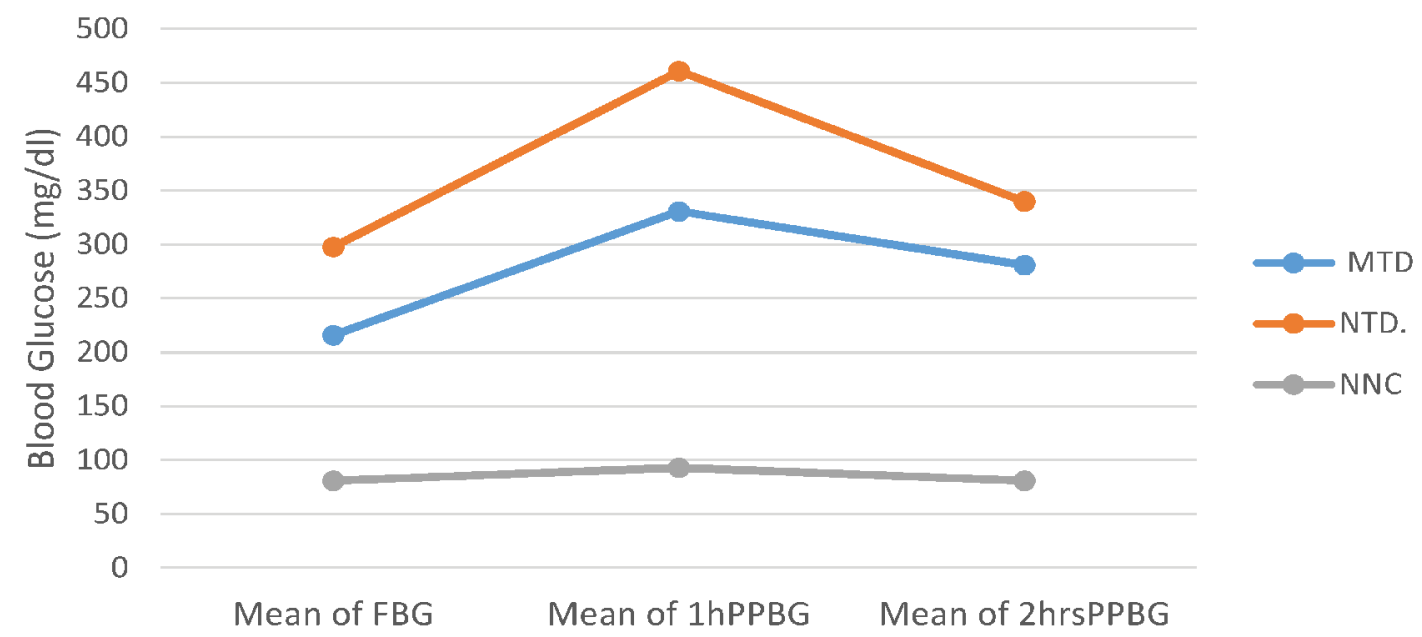

Figure 1: OGTT. 


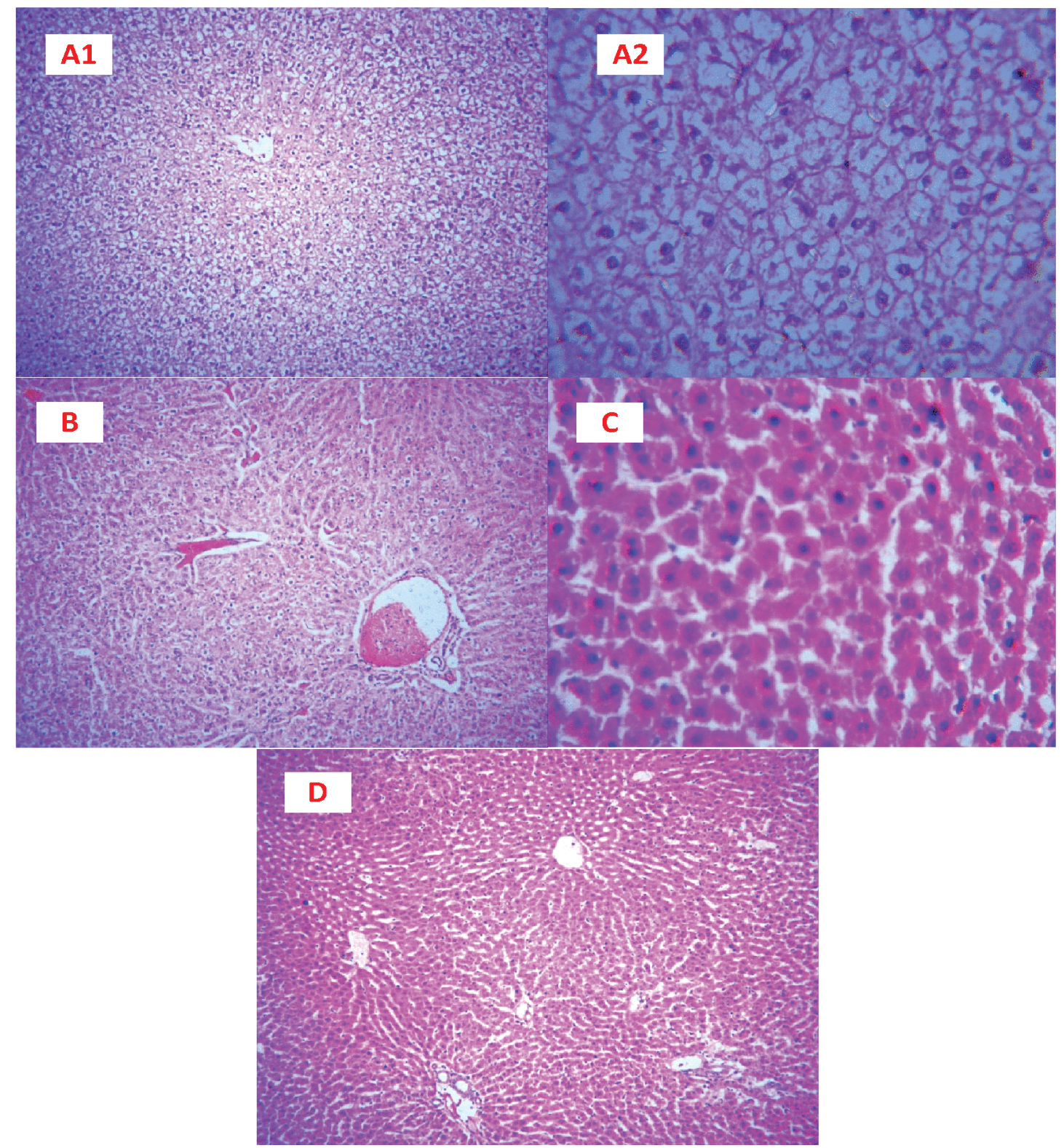

Figure 2: Histopathological findings.

A1: Liver section from NTD group showing diffuse vacuolar changes of hepatocytes (H\&E $\times 100)$; A2: Higher magnification of $A 1$ (Diffuse vacuolar changes of hepatocytes. H\&E $\times 400$ ); B: Liver section from $\mathrm{F} 1$ group revealing congestion of hepatic veins and mild vacuolar changes of the hepatocytes (H\&E $\times 100)$; C: Liver section from F1 group display focal area with acute swelling and dissociation of hepatocytes (H\&E $\times 400)$; D: Liver section from non-diabetic normal control: Liver parenchyma showing no significant changes (H\&E $\times 100)$.

Table 2: Level of IR in the skeletal muscles.

\begin{tabular}{|l|l|l|l|}
\hline Groups & MTD & NTD & NNC \\
\hline Mean of IR (IU/L) & $23.4 \pm 1.6$ & $24.7 \pm 2.4$ & $27 \pm 1.7$ \\
\hline
\end{tabular}

Downregulation of IR was significant in MTD $(P$ value $=0.01)$ while it was insignificant in NTD (P value $=0.06)$.

mild congestion and dilation of the central veins. Vacuolation in this group was diffused and affect almost all rats. MTD showed insignificant vacuolation (found in some rats) which was compatible with hyperglycemia. Regarding (FI) group, rats showed significant congestion of the central vein and mild swelling of hepatocytes with irregularity and insignificant vacuolation Figure 2.

\section{Detection of IR by Elisa}

Insulin receptor is a critical site for assessment of insulin sensitivity. Downregulation of $I R$ is a feature of T2DM. In our study IR was reduced in diabetic rats compared with the NNC yet, reduction was significant in skeletal muscles of MTD ( $P$ value $=0.01)$ whereas it was insignificant in NDC group ( $P$ value $=0.06)$. Table 2 and Figure 3.

\section{Discussion}

The increasing prevalence, morbidity and mortality of T2 DM, beside high tendency to develop both shortand long-term complication, require extensive research. In this study, we investigated causative factors that may contribute to the development of histopathological changes found in STZ-NA diabetic rats. We also assessed STZ-NA as a model of T2DM by measuring many factors like: hyperglycemia, amelioration of hyperglycemia by 


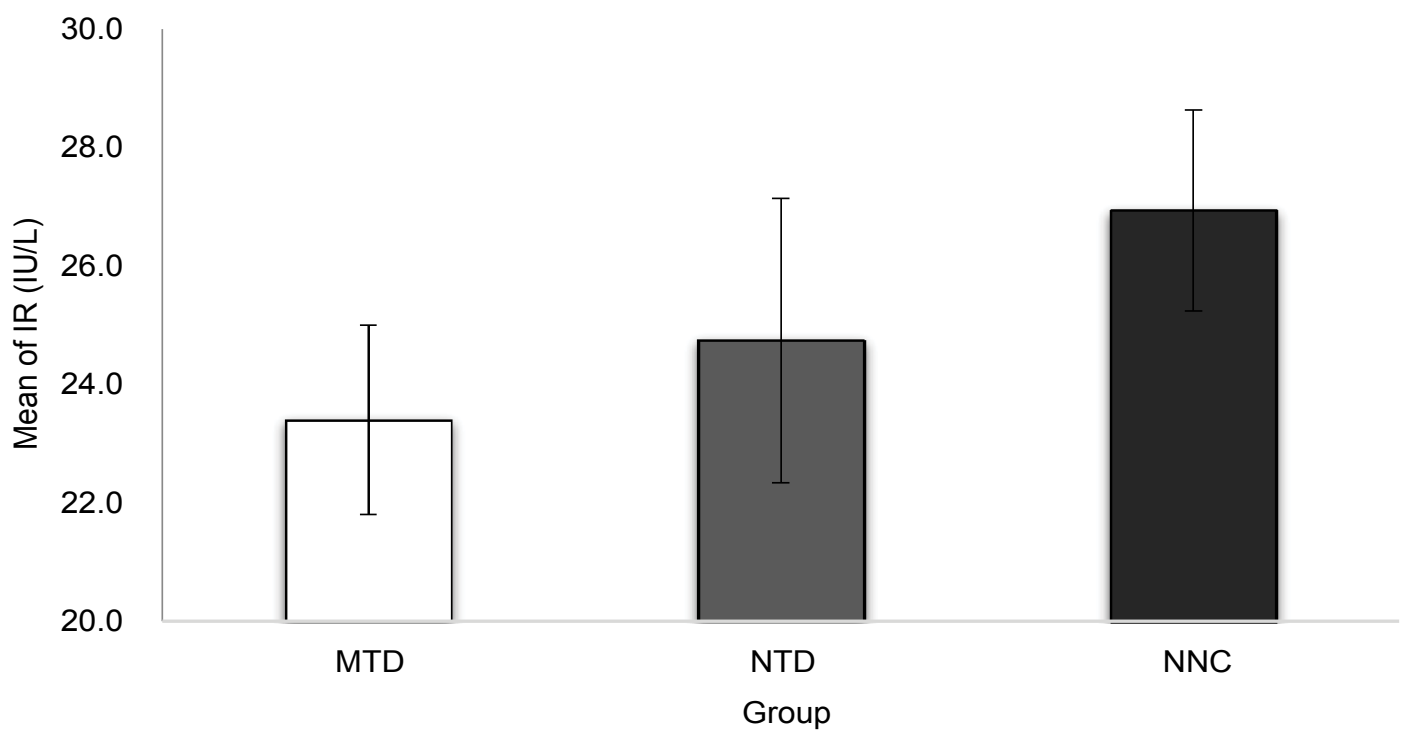

Figure 3: Level of IR in skeletal muscles.

metformin, lipid profile, IR and hepatic histopathological changes in relation to hyperglycemia.

STZ is selectively toxic to beta cells however, in our study it was combined with nicotnamide which partially protects beta cell. Combination of STZ and NA led to a high percentage of failure of induction which is compatible with Alenzi F. Q [32]. STZ- NA diabetic models resembles T2DM in many aspects some of which are loss of the early phase of glucose stimulated insulin release, reduction in pancreatic insulin [12] and reduction of insulin receptors in the skeletal muscles [28]. The prolonged hyperglycemia is a feature of T2DM that results from insufficiency of insulin function (insensitivity) as well as gluconeogenesis [33]. In our study, Hyperglycemia was prolonged $(\mathrm{FBG}=298 \pm 117,1 \mathrm{hr} \mathrm{PP}=461 \pm$ 88 and 2 hrs PP $=340 \pm 113$ ) in NTD group this is homogenous with T2DM. Unlike type 1 diabetes mellitus, T2DM usually respond well to oral hypoglycemic drugs [34]. Improvement of hyperglycemia by administration of metformin emphasizes that STZ-NA diabetic animal model mimics T2DM.

Defective lipolysis is a common feature of T2DM that may be manifested by Low HDL-C [28]. In our study, HDL-C was significant low in NTD group. This finding is consistent with Ghiasi R, et al. who induced T2DM by STZ-high fat diet [35]. Assembly of all factors above confirms the use of this induced animal model as a model of T2DM.

Histoplathological alteration found in STZ diabetic rats could be due to STZ or diabetes. STZ affects the liver, because hepatocytes express GLUT2 [10]. The mechanism by which STZ and diabetes affect the liver could be through increased ROS liberation [36,37]. Hepatic changes seen in diabetic rats include hydropic degeneration [14] as well as congestion and dilation of the central vein [38]. Prolonged hyperglycemia incre- ases ROS by autoxidation of glucose which in turn leads to lipid peroxidation and membrane damage then can cause hydropic degeneration [39]. To discriminate between hepatic histopathological changes caused by this toxic substance and diabetes mellitus, we compared the histopathological morphology of all groups with those rats with failure of induction (FI). Approximately all animals in the (FI) showed congestion of the central vein of hepatic lobules, swelling and dissociation of hepatocytes but mild insignificant vacuolation whereas NTD group showed massive vacuolation and mild congestion. MTD showed insignificant congestion and insignificant vacuolation, Metformin improved glycemic control and rats treated with metformin showed minor hepatic histopathological changes that were compatible with hyperglycemia emphasizing that hydropic degeneration was caused by diabetes. These findings are in a good agreement with several previous studies, which reported similar histopathological changes following induction of diabetes using STZ [40-42].

Downregulation of insulin receptor is compatible with T2DM. In our study, reduction of insulin receptor was significant in MTD whereas it was insignificant in the NTD. Reduction of insulin receptor in MTD confirms that its hypoglycemic effect is not a direct action on insulin receptor expression. On the other hand, it could be due to increase in insulin receptor activation as demonstrated by Gunton JE [43] or post receptor transduction effects [44]. The prolonged hyperglycemia, low HDL-C, response to metformin and the histopathological findings verified that STZ-NA diabetic rat represents a good animal model for T2DM.

\section{Acknowledgments}

We would like to extend our sincere gratitude and appreciation for all those helped us in this study especially Prof. Mohamed Tageldin Ibrahim Omer. 


\section{Conflicts of Interest}

None declared.

\section{Author Contribution}

Prof Imad Mohammedtahir and Prof Shadia Abdelatti were supervisors. They supervised the entire work.

Dr. Nahid Elamin was the researcher that worked under the supervision and guidance of the supervisors.

Dr. Hala Ali was the histopathologist that studied the hepatic histopathology.

\section{References}

1. Srinivasan K, Ramarao $P$ (2007) Animal models in type 2 diabetes research: An overview. Indian J Med Res 125: 451-472.

2. American Diabetes Association (2009) Diagnosis and Classification of Diabetes Mellitus. Diabetes Care 32: S62-S67.

3. Maiese K (2008) Diabetic stress: New triumphs and challenges to maintain vascular longevity. Expert Rev Cardiovasc Ther 6: $281-284$.

4. Deshpande AD, Harris-Hayes M, Schootman M (2008) Epidemiology of Diabetes and Diabetes-Related Complications. Phys Ther 88: 1254-1264.

5. Wu Y, Ding Y, Tanaka Y, Zhang W (2014) Risk factors contributing to type 2 diabetes and recent advances in the treatment and prevention. Int J Med Sci 11: 1185-1200.

6. Barré-Sinoussi F, Montagutelli X (2015) Animal models are essential to biological research: Issues and perspectives. Future Sci OA 1: FSO63.

7. Yalniz M, Pour P M (2006) Toxicology of the endocrine pancreas. Taylor and Francis group, Boca Raton, Florida, USA, 542-545.

8. Ghasemi A, Khalifi S, Jedi S (2014) Streptozotocin-nicotinamide-induced rat model of type 2 diabetes (review). Acta Physiol Hung 101: 408-420.

9. Nayak Y, Hillemane V, Daroji VK, Jayashree BS, Unnikrishnan MK (2014) Antidiabetic activity of benzopyrone analogues in nicotinamide-streptozotocin induced type 2 diabetes in rats. The Scientific World Journal.

10. Eleazu CO, Eleazu KC, Chukwuma S, Essien UN (2013) Review of the mechanism of cell death resulting from streptozotocin challenge in experimental animals, its practical use and potential risk to humans. J Diabetes Metab Disord 12: 60 .

11. Lalit K, Anu K, Navpreet K (2017) Role of Nicotinamide in Streptozotocin Induced Diabetes in Animal Models. Journal of Endocrinology and Thyroid Research 2.

12. Tahara A, Matsuyama-Yokono A, Nakano R, Someya $Y$, Shibasaki M (2008) Hypoglycaemic effects of antidiabetic drugs in streptozotocin-nicotinamide-induced mildly diabetic and streptozotocin-induced severely diabetic rats. Basic Clin Pharmacol Toxicol 103: 560-568.

13. Aboonabi A, Rahmat A, Othman F (2014) Antioxidant effect of pomegranate against streptozotocin-nicotinamide generated oxidative stress induced diabetic rats. Toxicol Rep 1: 915-922.

14. Gowda S, Desai PB, Hull VV, Math AA, Vernekar SN, et al. (2009) A review on laboratory liver function tests. Pan Afr Med J 3: 17
15. Giannini EG, Testa R, Savarino V (2005) Liver enzyme alteration: A guide for clinicians. CMAJ 172: 367-379.

16. Newsome PN, Cramb R, Davison SM, Dillon JF, Foulerton $M$, et al. (2018) Guidelines on the management of abnormal liver blood tests. Gut 67: 6-19.

17. Liu Y, Cheng Z, Ding L, Fang F, Cheng KA, et al. (2010) Atorvastatin-induced acute elevation of hepatic enzymes and the absence of cross-toxicity of pravastatin. Int $\mathrm{J}$ Clin Pharmacol Ther 48: 798-802.

18. Yaman T, Uyar A, Celik I, Alkan E, Keles OF, et al. (2017) Histopathological and Immunohistochemical Study of Antidiabetic Effects of Heracleum persicum Extract In Experimentally Diabetic Rats. Indian Journal of Pharmaceutical Education and Research 51: s450-s457.

19. Almansour M, Alarifi S, Jarrar B (2018) In vivo investigation on the chronic hepatotoxicity induced by intraperitoneal administration of $10-\mathrm{nm}$ silicon dioxide nanoparticles. Int J Nanomedicine 13: 2685-2696.

20. McNally PR (2010) GI/Liver secrets plus. (4 ${ }^{\text {th }}$ edn), Elsevier, Philadelphia, Pennsylvania, USA.

21. Soujanya S, Lakshman M, Kumar AA, Reddy AG (2013) Evaluation of the protective role of vitamin $C$ in imidacloprid-induced hepatotoxicity in male Albino rats. J Nat Sci Biol Med 4: 63-67.

22. Contreras CM, Brouquet A, Maru DM, Vauthey JN (2012) Hepatic steatosis, steatohepatitis, and chemotherapy-related liver injury. In: Jarnagin WR, Blumgart's Surgery of the Liver, Biliary Tract, and Pancreas. Elsevier, Philadelphia, USA.

23. Koh A, Lee MN, Yang YR, Jeong H, Ghim J, et al. (2013) $\mathrm{C} 1-\mathrm{Ten}$ is a protein tyrosine phosphatase of insulin receptor substrate 1 (IRS-1), regulating IRS-1stability and muscle atrophy. Mol Cell Biol 33: 1608-1620.

24. Watson RT, Pessin JE (2001) Intracellular organization of insulin signaling and GLUT4 translocation. Recent Prog Horm Res 56: 175-193.

25. Guo S (2014) Insulin Signaling, Resistance, and the Metabolic Syndrome: Insights from Mouse Models to Disease Mechanisms. J Endocrinol 220: T1-T23.

26. Caruso M, Ma D, Msallaty Z, Lewis M, Seyoum B, et al. (2014) Increased interaction with insulin receptor substrate1, a novel abnormality in insulin resistance and type 2 diabetes. Diabetes 63: 1933-1947.

27. DeFronzo RA, Tripathy D (2009) Skeletal muscle insulin resistance is the primary defect in type 2 diabetes. Diabetes Care 32: S157-S163

28. Saini V (2010) Molecular mechanisms of insulin resistance in type 2 diabetes mellitus. World J Diabetes 1: 68-75.

29. Krauss RM (2004) Lipids and Lipoproteins in Patients With Type 2 Diabetes. Diabetes Care 27: 1496-1504.

30. Barter PJ (2011) The causes and consequences of low levels of high density lipoproteins in patients with diabetes. Diabetes Metab J 35: 101-106.

31. Survana SK, Layton Ch, Banchroft JD (2013) Theory and practice of histological techniques. ( $7^{\text {th }}$ edn), Churchill Livingstone, China.

32. Alenzi FQ (2009) Effect of Nicotinamide on Experimental Induced Diabetes. Iran J Allergy Asthma Immunol 8: 11-18.

33. Rizza RA (2010) Pathogenesis of fasting and postprandial hyperglycemia in type 2 diabetes: Implications for therapy. Diabetes 59: 2697-2707. 
34. Chaudhury A, Duvoor C, Reddy Dendi VS, Kraleti S, Chada A, et al. (2017) Clinical Review of Antidiabetic Drugs: Implications for Type 2 Diabetes Mellitus Management. Front Endocrinol (Lausanne) 8: 6.

35. Ghiasi R, Ghadiri Soufi F, Somi MH, Mohaddes G, Mirzaie Bavil F, et al. (2015) Swim Training Improves HOMA-IR in Type 2 Diabetes Induced by High Fat Diet and Low Dose of Streptozotocin in Male Rats. Adv Pharm Bull 5: 379-384.

36. Raza H, John A (2012) Streptozotocin-induced cytotoxicity, oxidative stress and mitochondrial dysfunction in human hepatoma HepG2 cells. Int J Mol Sci 13: 5751-5767.

37. Low Wang CC, Hess CN, Hiatt WR, Goldfine AB (2016) Clinical Update: Cardiovascular disease in diabetes mellitus: atherosclerotic cardiovascular disease and heart failure in type 2 diabetes mellitus - mechanisms, management, and clinical considerations. Circulation 133: 2459-2502.

38. Imad M Al-Ani, Ahmed N Abired, Basma E Mustafa, Emad N Abdel Wahab, Marwan S Azzubaidi (2017) Effect of flaxseed extract on the liver histological structure in streptozotocin induced diabetic rats. International Medical Journal Malaysia 6: 91-98.

39. Tolman KG, Fonseca V, Dalpiaz A, Tan M (2007) Spectrum of liver disease in type 2 diabetes and management of pa- tients with diabetes and liver disease. Diabetes Care 30: 734-743.

40. Sheweita SA, Mashaly S, Newairy AA, Abdou HM, Eweda SM (2016) Changes in oxidative stress and antioxidant enzyme activities in streptozotocin-induced diabetes mellitus in rats: Role of alhagi maurorum extracts. Oxidative Medicine and Cellular Longevity.

41. Jessica GG, Mario GL, Alejandro Z, Cesar APJ, Ivan JVE, et al. (2017) Chemical characterization of a hypoglycemic extract from cucurbita ficifolia bouche that induces liver glycogen accumulation in diabetic mice. Afr J Tradit Complement Altern Med 14: 218-230.

42. Motshakeri M, Ebrahimi M, Goh YM, Othman HH, Hair-Bejo $M$, et al. (2014) Effects of brown seaweed (sargassum polycystum) extracts on kidney, liver, and pancreas of type 2 diabetic rat model. Evid Based Complement Alternat Med.

43. Gunton JE, Delhanty PJ, Takahashi S, Baxter RC (2003) Metformin rapidly increases insulin receptor activation in human liver and signals preferentially through insulin-receptor substrate-2. J Clin Endocrinol Metab 88: 1323-1332.

44. Mackenzie RWA, Elliott BT (2014) Akt/PKB activation and insulin signaling: A novel insulin signaling pathway in the treatment of type 2 diabetes. Diabetes Metab Syndr Obes 7: 55-64. 